Delft University of Technology

\title{
11th International Symposium on Particle Image Velocimetry (PIV 2015)
}

Christensen, K. T.; Scarano, F.

DOI

10.1088/1361-6501/28/1/010103

Publication date

2017

Document Version

Final published version

Published in

Measurement Science and Technology

\section{Citation (APA)}

Christensen, K. T., \& Scarano, F. (2017). 11th International Symposium on Particle Image Velocimetry (PIV 2015). Measurement Science and Technology, 28(1), [010103]. https://doi.org/10.1088/1361$6501 / 28 / 1 / 010103$

\section{Important note}

To cite this publication, please use the final published version (if applicable).

Please check the document version above.

\section{Copyright}

Other than for strictly personal use, it is not permitted to download, forward or distribute the text or part of it, without the consent of the author(s) and/or copyright holder(s), unless the work is under an open content license such as Creative Commons.

\section{Takedown policy}

Please contact us and provide details if you believe this document breaches copyrights.

We will remove access to the work immediately and investigate your claim. 
11th International Symposium on Particle Image Velocimetry (PIV 2015)

This content has been downloaded from IOPscience. Please scroll down to see the full text. 2017 Meas. Sci. Technol. 28010103

(http://iopscience.iop.org/0957-0233/28/1/010103)

View the table of contents for this issue, or go to the journal homepage for more

Download details:

IP Address: 131.180.130.242

This content was downloaded on 28/02/2017 at 10:04

Please note that terms and conditions apply. 


\section{Editorial}

\section{1th International Symposium on Particle Image Velocimetry (PIV 2015)}

\section{Guest Editors}

\section{K T Christensen}

Aerospace and Mechanical

Engineering Department;

Civil and Environmental

Engineering and Earth

Sciences Department,

University of Notre Dame,

Notre Dame, IN USA

E-mail: christensen.33@nd.edu

\section{F Scarano}

Aerospace Engineering

Department, Delft University

of Technology, Delft, The

Netherlands

E-mail: f.scarano@tudelft.nl
The particle image velocimetry (PIV) technique for measuring fluid velocity fields in flow domains has evolved into a primary measurement technique for studying complex flow phenomena across a broad scope of scientifically and societally relevant applications. With this rapid development and growing implementation of PIV, the International Symposium on Particle Image Velocimetry has become a key venue for the dissemination of PIV method developments and novel implementations of these methods to elucidate flow physics. The most recent installation of this meeting, the 11th International Symposium on Particle Image Velocimetry (PIV 2015), was held in Santa Barbara, California on September 14-16, 2015. This special feature of Measurement Science and Technology contains a selection of contributions from PIV2015 that focus upon new advancements of PIV measurements and analysis techniques.

The PIV technique combines the view of the instantaneous velocity pattern (in the spirit of flow visualization) with quantitative velocity data, oftentimes with sufficient temporal resolution to capture the dominant flow dynamics. Thus, PIV data is often utilized to support the development of numerical or phenomenological models of complex flow phenomena as well as for the validation of computational simulations of such flows. In this latter regard, the fidelity of the PIV data defines the reliability of the validation performed. Thus, PIV 2015 served as a venue for dissemination of the latest measurements and analysis advances meant to improve the quality and resolution of the data as well as more robust quantification of the inherent uncertainties associated with PIV data sets. Many of the conference contributions focused on improving the quantity and/or quality of data acquired (increased dimensionality, improved spatial and temporal resolution, new measurement methodologies) $[3,4$, 8-11, 17, 19, 21], development of more accurate and/or efficient data reduction methodologies $[1,6,7,13-16,22]$, and the development of robust uncertainty quantification methods meant to more objectively assess and document measurement uncertainties for verification and validation purposes $[2,5,12,18,20]$. The contributions included in this special feature span this broad spectrum of measurement and analysis advances, and we wish to thank all contributors for their willingness to publish their work in Measurement Science and Technology.

\section{References}

[1] Earl T, Jeon Y J, Lecordier B and David L 2016 F2DPR: a fast and robust cross-correlation technique for volumetric PIV Meas. Sci. Technol. 27084007

[2] Pan Z, Whitehead J, Thomson S and Truscott T 2016 Error propagation dynamics of PIV-based pressure field calculations: how well does the pressure poisson solver perform inherently? Meas. Sci. Technol. 27084012

[3] Satake S-I, Unno N, Nakata S and Taniguchi J 2016 3D measurement of gold particle via evanescent digital holographic particle tracking velocimetry Meas. Sci. Technol. 27084009

[4] Deem E, Zhang Y, Cattafesta L, Fahringer T and Thurow B 2016 On the resolution of plenoptic PIV Meas. Sci. Technol. 27084003

[5] van Overbrüggen T, Klaas M, Soria J and Schroeder W 2016 Experimental analysis of particle sizes for PIV measurements Meas. Sci. Technol. 27094009

[6] Fahringer T and Thurow B 2016 Filtered refocusing: a volumetric reconstruction algorithm for plenoptic-PIV Meas. Sci. Technol. 27094005

[7] Fuchs T, Hain R and Kaehler C 2016 In situ calibrated defocusing PTV for wall-bounded measurement volumes Meas. Sci. Technol. 27084005

[8] Tien W-H 2016 Development of multi-spectral 3D micro particle tracking velocimetry Meas. Sci. Technol. 27084010 
[9] Michaelis D, Neal D and Wieneke B 2016 Peak-locking reduction for PIV Meas. Sci. Technol. 27104005

[10] Eden A, Sigurdson M, Mezic I and Meinhart C 2016 A hybrid experimental-numerical technique for determining 3D velocity fields from planar 2D PIV data Meas. Sci. Technol. 27094010

[11] Ninomiya N, Kubo Y, Barada D and Kiire T 2016 3D velocity measurement by a single camera using Doppler phase-shifting holography Meas. Sci. Technol. 27104004

[12] Sciacchitano A and Wieneke B 2016 PIV uncertainty propagation Meas. Sci. Technol. 27084006

[13] Castrillo G, Discetti S and Astarita T 2016 Blob-enhanced reconstruction technique Meas. Sci. Technol. 27094011

[14] Yegavian R, Leclaire B, Champagnat F, Illoul C and Losfeld G 2016 Lucas-Kanade fluid trajectories for time-resolved PIV Meas. Sci. Technol. 27084004

[15] Barbu I and Herzet C 2016 A new approach for volume reconstruction in TomoPIV with the alternating direction method of multipliers Meas. Sci. Technol. 27104002

[16] Cornic P, Illoul C, Cheminet A, Le Besnerais G, Champagnat F, Le Sant Y and Leclaire B 2016 Another look at volume self-calibration: calibration and self-calibration within a pinhole model of Scheimpflug cameras Meas. Sci. Technol. 27094004

[17] Gurung A, Haverkort J, Drost S, Norder B, Westerweel J and Poelma C 2016 Ultrasound image velocimetry for rheological measurements Meas. Sci. Technol. 27094008

[18] Boomsma A, Bhattacharya S, Troolin D, Pothos S and Vlachos P 2016 A comparative experimental evaluation of uncertainty estimation methods for two-component PIV Meas. Sci. Technol. 27094006

[19] Jun B, Giarra M, Yang H, Main R and Vlachos P 2016 Nanoparticle flow velocimetry with image phase correlation for confocal laser scanning microscopy Meas. Sci. Technol. 27104003

[20] Foss J, Hedden M, Barros J and Christensen K 2016 A topological evaluation procedure to assess the integrity of a PIV vector field Meas. Sci. Technol. 27094007

[21] Ding L and Adrian R $2016 \mathrm{~N}$-pulse PIV-accelerometry for unsteady flow-structure interaction Meas. Sci. Technol. 28014001

[22] Aguera N, Cafiero G, Astarita T and Discetti S 2016 Ensemble 3D PTV for high resolution turbulent statistics Meas. Sci. Technol. 27124011 